\title{
Dorsomedial Thalamotomy (IV): Somatic Side-effects following Operation.
}

\author{
By
}

\author{
Toyoji Wada and Ryohei Aneha \\ （和田豐治）(姉缹量平)
}

(From the Department of Neuropsychiatry, Tohoku University, Sendai. Director: Prof, T. Ishibashi.)

(Received for publication, March 19, 1951)

Although the description on the complications of dorsomedial thalamotomy, ${ }^{3)}$ or a surgical invasion to the dorsomedial part of thalamus, is the purpose of this report, it would be interesting to note the clinical relationships between thalamotomy and thalamic syndrome. ${ }^{11}$ In other hand, if there were introduced severe complications by operation, it is obvious that thalamotomy is inapplicable for clinical usage. Certain answers to thses problems are made as conclusion in this paper, basing upon the clinical observations, from one month to a half year after operation, of the subjects consisting of 41 cases of various psychoses.

\section{Clinical Findings.}

Among 41 cases, one case had died owing to the haemorrhage of hypothalamic part, on which an autoptic photograph is shown in Fig. 1. In 5 cases which were thalamotized alone, and 2 cases, thalamotized after performance of prefrontal lobotomy operation undertaken 3 , or more, months ago, there occurred such disturbances that might be possible to say as hemiplegia, accompanying weakness of motility and hypesthesia of the unilateral extremities. Among them, each of 3 cases showed remarkable foot clonus and Babinski'reflex, and also, slight distrubance of light reflex of pupil. Those hemiplegia and symptoms of pyramidal system are seemingly introduced by the impairment, perhaps the lesions of internal capsule, due to technical failure; those patients showed psychic excitation during operation and, accordingly, the position of inserted thalamotome shifted in accordance with an abrupt, active movement of the head. However, those symptoms of pyramidal system had in each case reached till an almost complete recovery with gradual improvement within a half year.

In the remaining 33 cases, in which such 9 cases that had been lobotomized in former days, are included, the main side-effects recognizable 


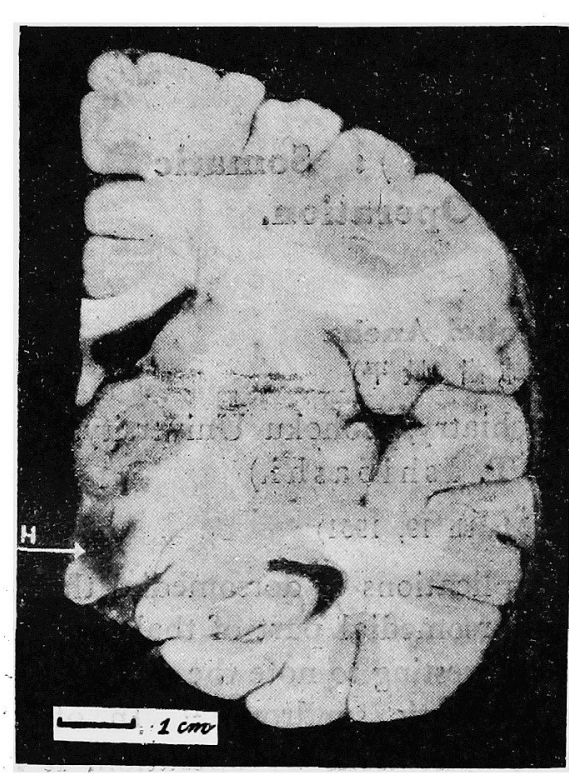

Fig. 1. Frontal section of the brain in one case of genuine epilepsy, which had died owing to the haemorrhage $(\mathrm{H})$ of hypothalamic part following thalamotomy operation. after operation are as shown in the following table.

Immediately after operåtion, there occurred such a disturbance of consciousness that continued for one or 2 days, however its rate and intensity were insignificant, when compared with that usually observable in the lobotomized cases. In several cases, disorientation was recognized, though it was generally incomplete. A tendency toward urinary incontinence continuing for one or 2 days was also observed, and in one case which was a deteriorated schizophrenia, this disturbance had continued for almost one month, though inconstantly. In function of reflex, a tendency toward increasing, even accompanying occasionally a transient appearance of pathologic reflexes, was dominant, but such symptoms did

\begin{tabular}{l|c|c}
\hline Symptom which was recognized & $\begin{array}{c}\text { Within one wéek after } \\
\text { operation }\end{array}$ & $\begin{array}{c}\text { 20 days after } \\
\text { operation }\end{array}$ \\
\hline Disturb. of conscious. & $13(5)$ & $0(0)$ \\
Urinary incontinence & $5(6)$ & $0(1)$ \\
Reflex $\left\{\begin{array}{l}\text { increasing } \\
\text { decreàsing }\end{array}\right.$ & $13(5)$ & $0(0)$ \\
Headache & $3(0)$ & $0(0)$ \\
Xanthochromia & $24(9)$ & $0(0)$ \\
Ataxia (static) & $20(9)$ & $0(0)$ \\
\end{tabular}

Sygns in parenthese indicate the data from 9 cases which were lobotomized in former days, such as 3 , or more, months before application of thalamotomy.

not continue for more than 10 days, especially pathalogic reflexes were temporary.

-Almost all cases were used to complain of severe headache for one week after operation, or until dischárge of cerebbrospinal liquid' was performed: in fact, this symptom was used to disappear immediately after performance of lumbal puncture. The liquid discharged in the first one week after operation was in almost all cases xanthochromic, occasionally haemorthagic Accordingly, an increasing of liquid pressure, perhäps 
due to haemorrhage within the cerebral ventricles owing to surgical manipulation, might be considerable as one of genesis of occurrence of such a symptom. Differing from this headache, there was another headache which occurred in almost all cases during operation. It was a severe, intolerable pain without exact localization, continuing only during incisioning manipulation by means of thalamotome. Though this pain of the head accompanies with sweating and redishness of the face, it is seemingly a certain central pain having some accordances with the so-called thalamic pain.

An occurrence of ataxia, though it was in the main static one, was relatively dominant. However, this symptom tended also reduce with gradual course and extinguished till one month after operation as shown in Fig. 2. Disturbances of sensation were generally insignificant. Owing to disturbance of consciousness, its exact recognition in the early stage after operation 'was difficult, though its occurrence seemed to be considerable to exist. Hypersthesia or hyperalgesia did not occur, but in one case, a complain of paresthesia, such as paralgesia of the unilateral arm, was recognized for several days following operation. In the cases having ataxia, hypesthesia accompanied with sensation of weakness of motility of the extremities was observed from one to 2 weeks. At the same time, such subjects were in general used to complain of drop of grip strength, however its measurment by means of dynamometer did not show so remarkable decrease. By this reason, in cases having such symptoms, certain concernings with the disturbance in sphere of deep sensation, rather than simple alternation of superficial sensation, seem-

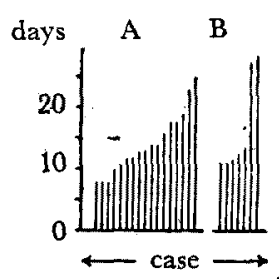

Fig. 2. Vicissitude of ataxia following thalamotomy operation. A:the cases manipulated thalamotomy alone: $B$ : the cases received thalamotomy after application of prefrontal lobotomy made in former days. ed to be impossible to deny, however an exact existence of disturbance of deep sensation was somewhat obscure. Such disturbances of sensation were transient and also used to extinguish prior to disappearance of ataxia, excepting of cases having hemiplegia. In addition, we have not experienced yet an occurrence of epileptic seizures due to thalamotomy.

\section{Discüssion.}

In comparison with the report made by Spiegel et al ${ }^{2}$ on somatic side-effects following thalamotomy operation, there exists a great deal of resemblances ${ }^{4}$ and lacks of any significant differences, excepting of occurrence of ataxia and headache.

In general, complication following thalamotomy operation might 
be said as slight, since it was transient and tended to extinguish, And, the occurred symptoms seemed somewhat differ from the thalamic syndrome. For example, there, according to our findings, lacked of occurrence of abnormal movement of the body, or of appearance of taxia with astereognosis or loss of sensation. In conclusion, these matters, or the above described findings, might admit to say that there exists a possibility of thalamotomy in clinical usage.

It was impossible to deny that there occurred a certain state of inertia following operation, since decreasing of appetite and weight was in all cases observed, in spite of that an increasing of temperature above $38.5^{\circ} \mathrm{C}$ was not recognized. We have thought, accordingly, that the compiete recovery of the somatic condition from influences of operation might need at longest one month after operation.

\section{SUMMARY.}

As complication of dorsomedial thalamotomy, hemiplegia, disturbance of consciousness, urinary incontinence, abnormality of reflex function, slight ataxia, slight disturbance of sensation, decreasing of appetite and weight, severe headache, etc. were observed, however excepting of hemi.plegia, those side-effects seemed to be transient and to tend to extinguish within about a half month after operation. In adding to an existence of possibility of thalamotomy for clinical practice, that complete recovery of somatic condition might need at longest one month after operation, was concluded.

\section{References and Notes.}

1) Langworthy and Fox, Arch. int. Med., 1937 60, 203.

2) Spiegel, Wycis and Freed, New York State J. Med., 1949, 49, 2273.

3) Wada, Folia Psychiat. Neurol. Japon., 1951, 4, 309,

4) This item may indicate that the principles on thalamotomy operation might eventually same, though the techniques for operation differ between Spiegel and his collaborators and the authors. 